McCaughey, W.T.E. (1958) Primary tumours of the pleura. Journal of Pathology and Bacteriology, 86, 517.

Newhouse, M.L. \& Thompson, H. (1965) Mesothelioma of the pleura and peritoneum following exposure to asbestos dust in the London area. British Journal of Industrial Medicine, 22, 261.

Nixon, P.F., Wolfenden, W.H. \& Hirst, E. (1964) Paraplegia and destruction of the ribs. Medical Journal of Aust ralia, 1, 207.

OWEN, W.G. (1964) Diffuse pleural mesothelioma and exposure to asbestos dust in the Merseyside area. British Medical Journal, 2, 214.

Ratzer, E.R., Pool, J.L. \& Melamed, M.R. (1967) Pleural mesotheliomas. Clinical experience in 37 patients. American Journal of Roentgenology, Radium Therapy, and Nuclear Medicine, 99, 863.

Selikoff, I.J., Churg, J. \& Hammond, E.C. (1965) Relation between asbestos expsoure and neoplasia. New England Medical Journal, 272, 560.

Semb, G. (1963) Diffuse pleural mesothelioma. A clinicopathological study of 10 fatal cases. Acta chirurgica scandinavica, 126, 78.

Spencer, H. (1962) Pathology of the Lung, p. 730. Pergamon Press: London.

Stout, A.P. \& MURRAY, M.R. (1942) Localized pleural mesothelioma. Investigations of its characteristics and histogenesis by the method of tissue culture. Archives of Pathology, 34, 951.

WAGner, J.C., Munday, D.E. \& Harrington, J.S. (1962) Histochemical demonstration of hyaluronic acid in pleural mesotheliomas. Journal of Pathology and Bacterio$\log y, 84,73$.

WAGNER, J.C. (1962) Experimental production of mesothelial tumours of the pleura by implantation of dusts in laboratory animals. Nature, 196, 180.

WILlIS, R.A. (1938) A metastatic deposit of bronchial carcinoma in a hydrocoel misdiagnosed 'endothelioma', with a review of supposed 'endotheliomas' of serosal membranes. Journal of Pathology and Bacteriology, 47, 253.

WILlis, R.A. (1952) Spread of Tumours in the Human Body. First edition, pp. 55. London.

Willis, R.A. (1967) Pathology of Tumours. Fourth edition, pp. 181. London.

WINSLOW, D.J. \& TAYLOR, H.B. (1960) Malignant pleural mesotheliomas. A clinico-pathological analysis of 12 cases. Cancer, 13, 127.

Whitwell, F. \& RAwCLIFFE, R.N. (1971) Diffuse malignant pleural mesothelioma and asbestos exposure. Thorax, 26, 1.

\title{
Antepartum diagnosis of vasa praevia-report of a case causing sudden foetal death
}

\author{
C. S. Pallewela \\ M.B., M.R.C.O.G. \\ Maternity Hospital, South Shields
}

\begin{abstract}
Summary
A case of sudden foetal death due to vasa praevia is reported. The main problem is early ante-partum diagnosis. Three methods are discussed.

(1) Tests to recognize foetal blood as a routine in ante-partum haemorrhage;
\end{abstract}

(2) amnioscopy before amniotomy; in foetal irregularity or bradycardia; in ante-partum haemorrhage;

(3) tests for foetal bradycardia in early labour as a part of the routine abdominal examination.

\section{Introduction}

Vasa praevia is a rare obstetric complication which must be kept in mind as a rare cause of antepartum haemorrhage. Less than a hundred cases

Reprint requests to: Dr C. S. Pallewela, Hemel Hempstead General Hospital, Hemel Hempstead, Herts. have been reported in the literature. It causes two symptoms-foetal bradycardia when a vessel is compressed, and a haemorrhage when the vessel is torn. Severe bradycardia will lead to Caesarean section for foetal distress of probably 'unknown' origin-the infant may be saved, the cause of the foetal distress only being apparent on inspection of the placenta after the operation.

Haemorrhage is dangerous to the foetus because the blood-loss is of foetal origin. What would be considered an insignificant haemorrhage if the bloodloss was maternal in origin would be lethal to the infant when foetal blood was lost-as illustrated by this case, where the foetal heart failed with the very first bout of bleeding. One difficulty in the management of ante-partum haemorrhage is to exclude the possibility of the blood-loss being of foetal origin. 


\section{Case report}

A 39-year-old woman, Gravida IV Para III. Three previous pregnancies uneventful, the last baby being born 12 years previously.

\section{Preliminary investigations}

WR and GCFT, negative. Blood group, $\mathrm{O}$ Rh. negative. $\mathrm{Hb}, 75 \%$. BP, $120 / 60$. Nothing abnormal detected in cardiovascular and respiratory systems. Pregnancy was uneventful until she was admitted in labour at the thirty-seventh week of gestation. Her general condition was satisfactory. Blood pressure $110 / 70$. On examination the height of the fundus was near term, presentation vertex-engaged. Internal examination revealed the cervix was taken up, os was 2 fingers dilated, membranes were intact. Vertex was engaged.

Three hours after admission, whilst in labour she had a brisk bleed of about $100 \mathrm{ml}$. The foetal heart was found to be absent almost simultaneously. Bleeding ceased after a few min. The foetal parts were easily palpable. There were no tender areas over her uterus. The consistency of the uterus felt normal, which clinically ruled out any likelihood of accidental haemorrhage. Vaginal examination at this stage showed the os was 2 fingers dilated, vertex engaged, and membranes ruptured. As the foetal heart had failed, labour was allowed to progress to delivery. Fifteen hours after admission the third stage was completed by Brandt-Andrew manoeuvre. Inspection of the placenta revealed a low velamentous insertion of the cord with a torn major vessel (Fig. 1).

The cause of the haemorrhage and the sudden

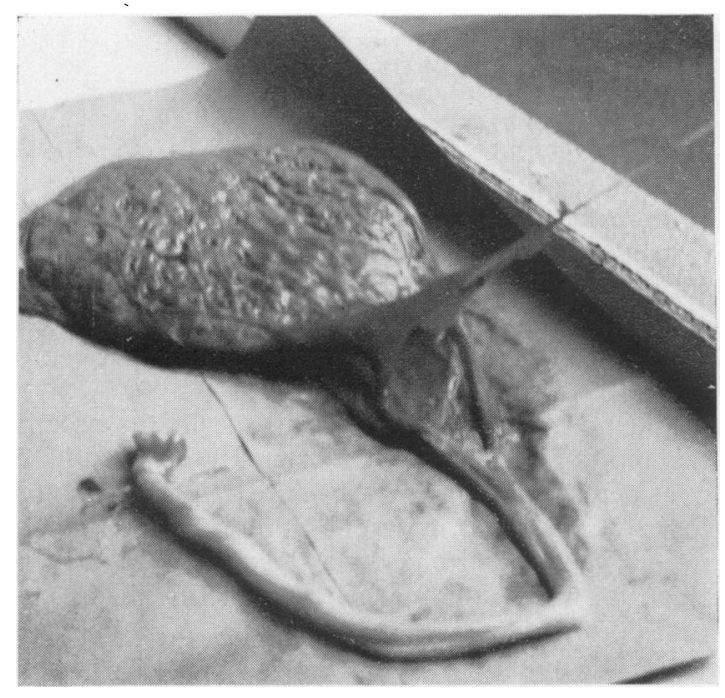

Fig. 1. failure of the foetal heart were found to be due to rupture of the membranes and a torn major vessel. The presenting part had compressed the vessel to prevent further bleeding.

The infant, male, weighed $8 \mathrm{lb} 6 \mathrm{oz} ; 22$ in long; head circumference 13 in. No abnormality externally evident. Unfortunately, the parents refused permission for autopsy.

\section{Discussion}

The foetal heart stopped almost simultaneously $\vec{\circ}$ with the short, brisk bleed. The problem of vasa praevia needs consideration. Once labour has started, the cervix opens leaving the membranes unsupported and rupture of the vasa praevia is almost inevitable. Once ante-partum haemorrhage occurs, there is little hope for the foetus, unless the possibility of the blood being of foetal origin is recognized. Some workers advise the Apt test (Apt and Downey, 1955) to distinguish foetal from maternal blood. An alternative is the Kleihauer test.

Naftolin and Mishell (1965) reported three cases of vasa praevia with the loss of one infant, but the diagnosis was made only after delivery. Curl and Johnson (1968) reported one case in which the pulsation of the vessels was detected at routine vaginal examination: a Caesarean section saved tho infant. Paulino (1970) reviewed the literature over 10-year period and reported six cases with one live. infant. Only in one instance was the vasa praevi diagnosed ante partum. Barham (1968) reported a case in which the vasa praevia was detected by amnioscopy; he recommends the procedure in the following instances: (a) before amniotomy (whatever the indication); (b) when foetal irregularity occurs in labour; (c) when unexplained ante-partum haemorrhage occurs.

If amnioscopy were done routinely in the above situations, it might be possible to make a diagnosis of vasa praevia before symptoms of foetal anoxia were manifest.

Inducing foetal bradycardia at early labour as a part of the routine abdominal examination may help to focus attention on those foetuses which are liable to get into distress. The foetal heart rate is taken between uterine contractions and then repeatedly during contraction while pressing the head well into the pelvis. If the rate falls steeply or the slow rate persists after the contraction has ceased, an extra $N$ careful watch is kept over the foetus. A presentation $N$ of the cord has been diagnosed by this method and $\stackrel{N}{N}$ could help in the ante-partum diagnosis of vasa praevia (Amarasinghe, 1970).

\section{References}

Amarasinghe, P.H. (1970) Personal communication. APT, L. \& DowneY, W. (1955) Melena neonatorum and 7 swallowed blood syndrome. Journal of Pediatrics, 47, 6. 
BARHAM, K.A. (1968) Diagnosis of vasa praevia by amnioscopy. Medical Journal of Australia, 2, 398.

Curl, C.W. \& Johnson, W.L. (1968) Vasa praevia: antipartum diagnosis of a case. Obstetrics and Gynecology, 31, 328.
Naftolin, F. \& Mishell, D.R., JR (1965) Vasa praevia. Report of three cases. Obstetrics and Gynecology, 26, 561.

Paulino, E.H. (1970) Clinical review of vasa praevia in a ten year period. Medical Annals of the District of Columbia, 251, 39.

Postgraduate Medical Journal (November 1974) 50, 725-726.

\title{
Traumatic aortic incompetence following road traffic accident
}

\author{
J. B. IRVING \\ B.SC., M.B., Ch.B., M.R.C.P. \\ Cardiac Department, Western General Hospital, Edinburgh
}

\begin{abstract}
Summary
This case report describes the presentation and treatment of a case of aortic incompetence, resulting from a road traffic accident. The relevant literature is briefly reviewed.

Aortic incompetence due to trauma has been described following non-penetrating chest injuries, such as kicks from horses (Barie, 1881), falls from heights and crushing accidents (Kissane, Koons and Clark, 1948; Levine, Roberts and Morrow, 1962). Despite the frequency of road traffic accidents, there have been no recent reports of traumatic aortic valve damage.
\end{abstract}

\section{Case history}

The patient, a 44-year-old transport manager, was admitted to hospital in September, 1972. He gave a history of increasing breathlessness on exertion over the previous 15 months. For the 2 months before admission he had complained of nocturnal dyspnoea. The symptom of breathlessness as well as episodes of dizziness had dated from May, 1971, when he had been involved in a serious road accident. The nature of the accident was such that, on impact, he had been thrown through the back window of his car, sustaining injuries to the upper thoracic spine and occipital part of the skull. He was unconscious for approximately $10 \mathrm{~min}$ and, on admistion to the casualty department, the principal abnormality was of tenderness, swelling and marked angulation of the thoracic spine. X-rays revealed a compression facture of the 7 th thoracic vertebra. No murmurs were noted and blood pressure was normal. Systolic and early diastolic murmurs were first noted 5 days after admission.

Following discharge the patient noted that he was breathless on climbing stairs and that he suffered quite marked light-headedness on more severe exercise.

In the past history, he had a myocardial infarction in 1968. During that admission only a soft systolic murmur was noted. There were no signs of aortic insufficiency, the heart was of normal size and the electrocardiogram showed normal left ventricular voltages. He was said to have had rheumatic fever at the age of 28, treated at home. Subsequent medical examinations in the Services were satisfactory.

On admission to hospital, he had signs of left ventricular failure and of gross aortic incompetence. Good progress was made on standard therapy but shortly after discharge he was re-admitted in acute pulmonary oedema and subsequently transferred for more specialized investigation.

\section{Examination}

The patient was pale, mildly dyspnoeic with marked Corrigan pulsations in the neck. Jugular venous pressure was elevated and a third sound was audible on auscultation. There was a loud aortic systolic murmur and long aortic diastolic murmur, both radiating to the neck and maximal over the upper left sternal border. Pulse was collapsing, sinus in rhythm, and blood pressure was $180 / 50$. There were bilateral fine crepitations in the chest.

\section{Investigations}

Chest X-ray showed cardiomegaly and pulmonary venous congestion and the ECG showed marked left ventricular hypertrophy. At cardiac catheterization, the left ventricular end diastolic pressure was $15-45 \mathrm{mmHg}$ and a supravalvular angiogram showed severe aortic incompetence. Coronary angiograms were normal except for minor narrowing of the left anterior descending artery. WR was negative. 